\title{
LAS CASAS-IGLESIAS EN EL CRISTIANISMO PRIMITIVO Y SUS IMPLICACIONES PARA EL DISCIPULADO URBANO ACTUAL
}

LIC. ERIC E. RICHTER

Centro Histórico Adventista, Universidad Adventista del Plata, Argentina 


\title{
Resumen
}

Las casas-iglesias en el cristianismo primitivo y sus implicaciones para el discipulado urbano actual. En sus inicios, el cristianismo primitivo se caracterizó por ser una religión predominantemente urbana. En contraste, la Iglesia Adventista del Séptimo Día surgió como un movimiento religioso rural $\mathrm{y}$ ha tenido dificultades para alcanzar los grandes centros urbanos con su mensaje. La presente investigación indaga sobre si la utilización de una de las estrategias evangelísticas del cristianismo primitivo, las casas-iglesias, puede ser de utilidad a la Iglesia Adventista del Séptimo Día actual para realizar evangelismo urbano. Con este objetivo, se realiza un análisis documental para determinar las características y beneficios de las casas-iglesias en el cristianismo apostólico. Luego se describen las implicancias de estas ventajas y su posible aplicabilidad en el contexto evangelístico urbano actual.

Palabras clave: misiología adventista, grupos pequeños, templo, evangelización urbana.

\begin{abstract}
Home-Churches in the Early Christianity and Their Implications for Urban Discipleship Today. Since its beginnings, the Early Christianity was predominantly an urban religion. In contrast, the Seventh-day Adventist Church emerged as a rural religious movement and has struggled to reach large urban centers with its message. The present paper investigates whether the use of one of the evangelistic strategies of early Christianity, the homechurches, can be useful to the current Seventh-day Adventist Church to carry out urban evangelism. With this objective, a documentary analysis is carried out to determine the characteristics and benefits of home-churches in apostolic Christianity. Then the implications of these advantages and their possible applicability in the current urban evangelistic context is developed.
\end{abstract}

Keywords: Adventist missiology, small groups, temple, urban evangelism.

Recibido: $17 / 08 / 2021$

Aceptado: 20/08/2021 


\title{
LAS CASAS-IGLESIAS EN EL CRISTIANISMO PRIMITIVO Y SUS IMPLICACIONES PARA EL DISCIPULADO URBANO ACTUAL
}

\author{
LIC. ERIC E. RICHTER \\ Centro Histórico Adventista, \\ Universidad Adventista del Plata, Argentina
}

\begin{abstract}
1. Introducción
Desde sus comienzos, la Iglesia Adventista del Séptimo Día (IASD) ha sido una religión predominantemente rural. ${ }^{1}$ Desde su surgimiento a partir del movimiento millerita a mediados del siglo XIX, el adventismo se difundió inicialmente en los poblados rurales de New England. ${ }^{2}$ Con el paso del tiempo, y a medida que el adventismo se esparcía por Norteamérica e iniciaba los primeros esfuerzos internacionales a fines del siglo XIX, las grandes urbes permanecían como campos casi impenetrables ante los avances evangelísticos adventistas. ${ }^{3}$ Esta futilidad de los esfuerzos misioneros en las grandes ciudades provocó sinceras preocupaciones en Ellen G. White y otros líderes adventistas. ${ }^{4}$
\end{abstract}

1 George R. Knight, Nuestra Iglesia: Momentos históricos decisivos (Doral, FL: Asociación Publicadora Interamericana, 2008), 146.

2 Arthur W. Spalding, Origin and History of Seventh-day Adventists (Washington DC: Review \& Herald, 1961), 1:143.

3 Floyd Greenleaf y Richard W. Schwarz, Portadores de Luz: Historia de la Iglesia Adventista del Séptimo Día (Buenos Aires: Asociación Casa Editora Sudamericana, 2012), 151152.

4 Felipe E. Tan, "Ellen G. White on City Missions", Journal of Adventist Mission Studies 11, no. 1 (2015): 113-125; George R. Knight, “Another Look at City Mission”, Adventist Review, diciembre de 2001, 25-30.

https://doi.org/10.17162/recm.v18i1-2.1536 
A pesar del paso del tiempo, actualmente persiste la misma preocupación ante la incapacidad de alcanzar con efectividad los millones que habitan en los grandes centros urbanos del mundo. ${ }^{5}$ La situación de la IASD contrasta notoriamente con el comienzo del cristianismo, que surgió como un movimiento religioso predominantemente urbano. En la mayoría de las grandes ciudades antiguas había presencia cristiana, mientras que las zonas rurales no consiguieron ser alcanzadas exitosamente. Incluso, con el paso de los siglos, la presencia cristiana en áreas rurales continuó siendo reducida y los campesinos en el Imperio Romano persistieron en sus prácticas religiosas tradicionales. De hecho, la palabra española actual "pagano" proviene del latín pāgus, que significa "aldeano" o "agricultor". ${ }^{6}$

Es claro que numerosos factores históricos, sociales, culturales, económicos, religiosos, entre otros; provocaron esta radical diferencia entre el inicio del cristianismo y el comienzo del adventismo. Dieciocho siglos de historia separan a ambos movimientos e indudablemente cualquier comparación histórica se verá severamente limitada por las enormes diferencias entre ambos períodos. No obstante, es posible que la utilización de los mismos métodos misioneros que el cristianismo usó para alcanzar a las ciudades de su tiempo puedan ser útiles para evangelizar las ciudades actuales. Para ser más específicos, este artículo se limita a explorar la eficacia y beneficios de las casas-iglesias en el cristianismo primitivo. Además de observar las ventajas que proporcionó a los cristianos apostólicos, se observan las posibles implicancias que el uso de esta metodología evangelística pueda tener para el discipulado urbano actual de la IASD.

Con el objetivo de abordar apropiadamente este tema, la presente investigación realiza un análisis de carácter documental y bibliográfico, con énfasis en las fuentes históricas primarias del cristianismo primitivo. De esta manera se pretende describir de qué manera el uso de las casas-iglesias benefició el discipulado urbano en el cristianismo primitivo y cómo una mejor comprensión de este fenómeno puede producir implicancias para el discipulado adventista del séptimo día en los grandes centros urbanos actuales.

\section{Consideraciones preliminares}

Antes de proceder al desarrollo del argumento central de este artículo, es preciso definir algunos conceptos básicos, así como delimitar el objeto de

5 Adventist World Staff, "To Reach the Cities: Church President Issues Impassioned Plea to Evangelize Urban Centers", Adventist World, diciembre de 2017, 5-6.

6 Santiago Segura Munguía, Lexicón etimológico y semántico del Latín (Bilbao: Publicaciones de la Universidad de Deusto, 2014), s.v. "pāgus", 472.

https://doi.org/10.17162/recm.v18i1-2.1536 
estudio para facilitar la viabilidad de la investigación. El tema de estudio es el rol de las casas-iglesias en la evangelización urbana durante el cristianismo primitivo y sus implicaciones para la actualidad.

Para empezar, es necesario aclarar que los cristianos primitivos no solo se reunían en hogares y casas, sino en otras ubicaciones como comercios, talleres, almacenes, establos y lugares públicos. ${ }^{7}$ Sin embargo, nos limitaremos al ambiente doméstico propio de las familias urbanas, excluyendo otras posibles locaciones.

La etapa primitiva del cristianismo abarca desde el año 31 d.C. hasta el año 313 d.C. aproximadamente. Es decir, desde el Pentecostés, en donde encontramos el origen de la iglesia cristiana, hasta la promulgación del Edicto de Milán. Esta limitación temporal se debe a que la legalización del cristianismo produjo un cambio eclesiológico que llevó al declive de las casas-iglesias como lugares de culto, reemplazándolas con edificios públicos. ${ }^{8}$

Al estudiar el evangelismo urbano nos enfocaremos en las grandes urbes antiguas del Imperio Romano, con énfasis a la esfera greco-romana de Asia Menor. La razón para este énfasis es que en Asia Menor fue donde el cristianismo tuvo mayor arraigue en sus primeras décadas.

Por último, se debe considerar que esta investigación no pretende analizar la relación entre las casas-iglesias antiguas y los grupos pequeños actuales. A pesar de que en la literatura adventista comúnmente se igualan ambos fenómenos, ${ }^{9}$ es claro que existen diferencias entre ambas modalidades (véase la Tabla 1). Por lo tanto, considerar al grupo pequeño como una continuación o correspondencia de las casas-iglesias es, sencillamente, un anacronismo histórico.

7 Por más información sobre los lugares en los que se reunían los primeros cristianos, véase Edward Adams, The Earliest Christian Meeting Places: Almost Exclusively Houses? (Londres: Bloomsbury, 2013).

8 Andrew B. McGowan, Ancient Christian Worship: Early Church Practices in Social, Historical, and Theological Perspective (Grand Rapids: Baker Academic, 2014), 59-60.

9 José Umberto Moura y Roberto Pereyra, “Los grupos pequeños en el Nuevo Testamento (círculo apostólico, cristianismo apostólico)", en Grupos pequeños: Profundizando la caminata, ed. por Jolivê Chaves y Alberto R. Timm (Buenos Aires: Asociación Casa Editora Sudamericana, 2011), 39; Santana Heron, Grupos pequeños, teoría y práctica (Buenos Aires: Asociación Casa Editora Sudamericana, 2009), 52; Viviana Lehoux y Walter Lehoux, En las manos de uno que no falla (Buenos Aires: Asociación Casa Editora Sudamericana, 2008), 32-33; David Cox, Pemse em grande, pense em grupos pequenos (Almargem do Bispo: Publicadora Atlántica, 2006), 6; Kurt W. Johnson, Grupos pequenos para el tiempo del fin: Una guía práctica para el siglo XXI (Buenos Aires: Asociación Casa Editora Sudamericana, 1999), 66-73; Miguel Ángel Cerna, El poder de los grupos pequeños en la iglesia (Newbury Park, CA: El Camino, 1991), 27-29.

https://doi.org/10.17162/recm.v18i1-2.1536 
Entre las diferencias principales debemos notar que la casa-iglesia era el lugar principal de reunión de los creyentes. En cambio, el grupo pequeño es considerado un lugar secundario de reunión, ya que complementa la reunión principal sabática que se realiza en el templo.

Las casas-iglesias, además, solían reunir entre 10 a 50 personas, dependiendo del tipo de residencia y su arquitectura. Mientras que los grupos pequeños usualmente no superan las 12 personas. ${ }^{10}$

Por último, debe señalarse que el uso de casas como lugares de reunión para la iglesia no resultó una estrategia previamente planificada, sino que surgió espontáneamente. Esto contrasta notablemente con la utilización de los grupos pequeños en la IASD, donde consisten de una estrategia evangelística planificada. ${ }^{11}$

Tabla 1 - Diferencias entre las casas-iglesias y los grupos pequeños

\begin{tabular}{|l|l|}
\hline \multicolumn{1}{|c|}{$\begin{array}{c}\text { Características de la casa-iglesia } \\
\text { primitiva }\end{array}$} & \multicolumn{1}{c|}{$\begin{array}{c}\text { Características del grupo } \\
\text { pequeño actual }\end{array}$} \\
\hline $\begin{array}{l}\text { Es el lugar principal de reunión de la } \\
\text { congregación. }\end{array}$ & $\begin{array}{l}\text { Es un lugar secundario o comple- } \\
\text { mentario de reunión. }\end{array}$ \\
\hline $\begin{array}{l}\text { Reunía entre 10 a } 50 \text { personas, sino } \\
\text { más. }\end{array}$ & Reúne de 8 a 12 personas. \\
\hline $\begin{array}{l}\text { Surge de intereses eclesiológicos y } \\
\text { pragmáticos. }\end{array}$ & Surge de intereses evangelísticos \\
\hline Es la iglesia & Es parte de la iglesia. \\
\hline
\end{tabular}

\section{Las casas-iglesias en el cristianismo primitivo}

De acuerdo al testimonio del NT, las primeras congregaciones cristianas se reunían en casas particulares. La primera reunión cristiana de la que tenemos registro congregó a cerca de 120 personas en el "aposento alto" de una

10 Melchor A. Ferreyra Castillo, Quiero organizar grupos pequeños, ¿que hago? (Buenos Aires: Asociación Casa Editora Sudamericana, 2003), 18.

11 No obstante, debe señalarse que entre nuestros pioneros la práctica de reunirse en los hogares era relativamente común. Véase Ricardo A. González, “Los grupos pequeños en la historia de la Iglesia Adventista del Séptimo Día", en Grupos pequeños: profundizando la caminata, ed. por Jolivê Chaves y Alberto R. Timm (Buenos Aires: Asociación Casa Editora Sudamericana, 2011), 71-82. 
"casa" (Hch 1:13; 2:2). ${ }^{12}$ Luego del Pentecostés, Lucas relata que los cristianos "día tras día continuaban unánimes en el templo y partiendo el pan en los hogares, comían juntos con alegría y sencillez de corazón, alabando a Dios y hallando favor con todo el pueblo" (Hch 2:46-47a). También tenemos registro de congregaciones cristianas que se reunían en la casa de Priscila y Aquila (Ro 16:5; 1 Co 16:19), de María, madre de Juan Marcos (Hch 12:12), de Ninfas en Laodicea (Col 4:15), de Gayo (Ro 16:23) y Filemón (Fil 1:2). La utilización de casas-iglesias incluso se ve reflejada en escritos extrabíblicos..$^{13}$ Por ejemplo, la Epístola de Clemente a Corinto (c. 95) y el Pastor de Hermas (c. 140) se encuentran enmarcadas en un "contexto social" definido por las casas-iglesias, ${ }^{14}$ al igual que con las Epístolas de Ignacio (c. 110). ${ }^{15}$ Las casas-iglesias también son mencionadas en los escritos de Clemente de Alejandría (c. 150-215), ${ }^{16}$ en los Hechos apócrifos de Pablo y Tecla (c. 150), ${ }^{17}$ en los Hechos apócrifos de Tomás (c. 225), ${ }^{18}$ en la Tradición Apostólica de Hipólito de Roma (c. 170-235), ${ }^{19}$ en la Didascalia Apostolorum (c. 275), ${ }^{20}$ y en El Martirio de Saturnino (304). ${ }^{21}$

\subsection{Origen}

Quizás limitar el origen de la práctica de reunirse en casas a un solo factor sea contraproducente. De hecho, la evidencia histórica parece sugerir tres

12 A menos que se indique algo diferentes, todas las citas bíblicas han sido tomadas de La Biblia de las Américas (1986).

13 Véase L. Michael White, The Social Origins of Christian Architecture (Valley Forge, PA: Trinity Press International, 1990), 1:33-120.

14 Karl P. Donfried y Peter Richardson, Judaism and Christianity in First-Century Rome (Grand Rapids: Eerdmans, 1998), 231-233.

15 Harry O. Maier, The Social Setting of the Ministry as Reflected in the Writings of Hermas, Clement and Ignatius (Toronto: Wilfried Laurier University Press, 2002), 156.

16 David A. Díaz Corrales y Jesús Flores Aparicio, “La iglesia de casa: Génesis e historia", en Para comprender la iglesia de casa: De la conservación a la misión (Estella: Verbo Divino, 2010), 90.

17 Plutarco Bonilla A., "Hechos de Pablo y Tecla”, Aportes Bíblicos 2 (2005): 12, 14.

18 Antonio Piñero y Gonzalo del Cetto, eds., Hechos apócrifos de los Apóstoles (Madrid: Biblioteca de Autores Cristianos, 2005), 2:136-139.

19 White, The Social Origins of Christian Architecture, 1:63-64.

20 Ibíd., 1:78-83.

$21 \quad$ Ibíd., 1:87-89. 
variables importantes que influyeron en la adopción de las casas-iglesias en el cristianismo primitivo. A continuación, se analizará cada una de ellas.

\subsubsection{Prácticas judías}

El primer factor a tener cuenta es que el judaísmo consideraba que el hogar poseía un rol igual, y, en ocasiones, incluso más importante que el de la sinagoga. ${ }^{22} \mathrm{~A}$ diferencia de las religiones greco-romanas, "la religión israelita se transmitía, se vivía y se celebraba principalmente en la casa" ${ }^{23}$ Las tradiciones rabínicas consideran loable que el dueño de una casa la utilice para la lectura y el estudio grupal de la Torá. ${ }^{24}$ Algunas de ellas terminaban convirtiéndose en las bet midrash o "casas de estudio", ${ }^{25}$ donde no solo se reunía el círculo familiar, sino también otros judíos e incluso prosélitos. ${ }^{26}$ Posiblemente algunas reuniones sinagogales también se realizaban en ambientes domésticos. ${ }^{27}$ De hecho, algunas sinagogas eran residencias domésticas remodeladas. ${ }^{28}$ Howard Clark Kee ha presentado considerable evidencia histórica y arqueológica para sugerir que la consolidación de la sinagoga

22 Miriam Peskowitz, “'Family/ies' in Antiquity: Evidence from Tannaitic Literature and Roman Galilean Architecture", en The Jewish Family in Antiquity, ed. Shaye J. D. Cohen (Atlanta, GA: Scholars Press, 1993), 9.

23 Santiago Guijarro Oporto, Fidelidades en conflicto: La ruptura con la familia por causa del discipulado y de la misión en la tradición sinóptica (Salamanca: Publicaciones Universidad Pontificia, 1998), 113. E. P. Sanders asegura que existían tres foci de la religión en el judaísmo del primer siglo: el Templo, la sinagoga y el hogar. E. P. Sanders, Judaism: Practice \& Belief, 63 BCE-66 CE (London: SCM Press, 1920), 48.

24 Alexei Sivertsev, Households, Sects, and the Origins of Rabbinic Judaism (Leiden: Brill, 2005), 180

25 Dan Jaffé, El Talmud y los orígenes judíos del cristianismo (Bilbao: Desclée de Brouwer, 2009), 39.

26 Aharon Oppenheimer, Between Rome and Babylon: Studies in Jewish Leadership and Society (Tübingen: Mohr Siebeck, 2005), 171-172.

27 Ekkehard W. Stegemann y Wolfgang Stegemann, Historia social del cristianismo primitivo (Estella: Verbo Divino, 2001), 342; Anders Runesson, Donald D. Binder y Birger Olsson, The Ancient Synagogue from its Origins to 200 C.E.: A Source Book (Leiden: Brill, 2008), 45.

28 Steven Fine, "From Meeting House to Sacred Realm: Holiness and the Ancient Synagogue", en Sacred Realm: The Emergence of the Synagogue in the Ancient World, ed. Steven Fine (New York: Oxford University Press, 1996), 25; Lee I. Levine, The Ancient Synagogue (New Haven, CT: Yale University Press, 2005), 119 (n. 197), 266; Peter Richardson, Building Jewish in the Roman East (Waco, TX: Baylor University Press, 2004), 138. 
como centro primario de instrucción religiosa sucedió luego del 70 d.C., y que previamente este rol lo desempeñaba primordialmente el hogar. ${ }^{29}$

\subsubsection{Consideraciones pragmáticas}

En segundo lugar, aunque es posible que los cristianos continuaran esta tradición judía de considerar el hogar como un lugar de reunión e instrucción religiosa por simple inercia, es claro que también fueron motivados por los beneficios prácticos que conllevaba. El uso de casas como lugares de reunión les permitía evitar los gastos financieros de construir edificios públicos para ese fin (como las sinagogas judías o los templos paganos). La residencia de cualquier creyente podía convertirse en un lugar de reunión, lo cual brindaba una flexibilidad y capacidad de adaptación que las demás religiones carecían. Por último, y tal vez más importante, las casas-iglesias se convertían en un excelente sistema de sobrevivir las persecuciones populares y gubernamentales. ${ }^{30}$ Cualquier hogar podría convertirse inmediatamente en un nuevo sitio para congregarse. Por lo tanto, los lugares de culto podrían ser reemplazados tan rápido como las autoridades perseguidoras del cristianismo cerraban los existentes.

\subsubsection{La costumbre de Jesús}

Finalmente, como último factor, debemos señalar que el fundador del cristianismo poseía una casa en Capernaúm donde se reunía con sus discípulos más cercanos para instruirlos y capacitarlos ( $\mathrm{Mr} 2: 1 ; 7: 17 ; 9: 28,33 ; 10: 10)$. Jesús también se hospedaba, predicaba y realizaba milagros en casas de otras personas (Mt 8:14; 9:10-11, 23, 28; 13:1, 36; 17:24-25; 26:6; Mr 1:29-30; $2: 15 ; 3: 20 ; 5: 38 ; 7: 24 ; 14: 3 ;$ Lc 4:38; 5:28; 7:36-37; 8:51; 14:1; 19:5). Los evangelios presentan al hogar como una locación fundamental en la predicación de Jesús y en la evangelización apostólica. ${ }^{31}$

La evidencia demuestra que, al menos en sus primeros siglos, el cristianismo era "una religión sin templos". ${ }^{32}$ Se consideraba que la comunidad

29 Howard Clark Kee, "The Transformation of the Synagoge after 70 C.E.: Its Import for Early Christianity", NTS 36 (1990): 1-24. Véase también Lee I. Levine, "The Nature and Origin of the Palestinian Synagogue Reconsidered", JBL 115, no. 3 (1996): 444448; Andrea M. Berlin, "Jewish Life Before the Revolt: The Archaeological Evidence", JSJ 36, no. 4 (2005): 425.

30 Cecil Stewart, Early Christian, Byzantine and Romanesque Architecture, vol. 2 de Simpson's History of Architectural Development (London: Longmans, 1954), 11.

31 Xabier Pikaza, Pan, casa, palabra: La iglesia en Marcos (Salamanca: Sígueme, 1988), 79142.

32 Díaz Corrales y Flores Aparicio, “La iglesia de casa”, 84. 
de creyentes era el "templo del Dios vivo" (2 Co 6:16, cf. Ef 2:19-22; 1 Co 3:17). El énfasis, por lo tanto, estaba en el grupo de personas y no en el espacio física donde se reunían.

\subsection{Arquitectura, estructura y organización}

Para la cultura greco-romana, "la familia era el elemento esencial de la sociedad", ${ }^{33}$ y el hogar era el "centro cúltico de la familia". ${ }^{34}$ Era normal que cada hogar cobijara un núcleo familiar extendido, ${ }^{35}$ donde la autoridad estaba en la cabeza de la familia.

El lugar físico donde habitaba cada familia dependía mayormente de su estatus social y económico. En el mundo greco-romano la mayoría de las personas de clase baja vivían en pequeños apartamentos llamados, en latín, insulae. ${ }^{36}$ Generalmente estos edificios se construían en complejos de hasta cuatro o cinco pisos alrededor de un patio central. ${ }^{37}$ La reunión en Troas descrita en Hechos 20:7-12 parece haberse realizado en una insulae. ${ }^{38}$ En cambio, en Palestina, las casas más humildes usualmente consistían en dos habitaciones alrededor o a los lados de un patio. ${ }^{39}$

Las casas greco-romanas de personas de clase alta, llamadas domus en latín, solían contener varias habitaciones alrededor de una habitación rectangular central, denominada atrium. ${ }^{40}$ Usualmente el atrium tenía una apertura en el techo y un pequeño estanque en su centro, llamado impluvium, donde se acumulaba el agua de la lluvia. ${ }^{41}$ En Palestina, mientras

$33 \quad$ Ibíd., 86

34 Maier, The Social Setting of the Ministry, 16.

35 Suzanne Dixon, The Roman Family (Baltimore, MD: The John Hopkins University Press, 1991), 4.

36 Díaz Corrales y Flores Aparicio, "La iglesia de casa”, 87.

37 Gregory Linton, "House Church Meetings in the New Testament Era", Stone-Campbell Journal 8 (2005): 235.

38 F. F. Bruce, The Book of the Acts, NICNT (Grand Rapids: Eerdmans, 1988), 385 (n. 28).

39 Margaret Williams, "The Jewish Family in Judaea from Pompey to Hadrian: The Limits of Romanization", en The Roman Family in the Empire: Rome, Italy and Beyond, ed. Michele George (New York: Oxford University Press, 2005), 165.

40 John R. Clarke, The Houses of Roma Italy 100 BC-250 AD: Ritual, Space, and Decoration (Berkeley, CA: University of California Press, 1991), 2-4.

41 Linton, "House Church Meetings", 237. 
tanto, las casas más pudientes solían tener habitaciones espaciosas alrededor de un patio central, donde no faltaba al menos un mikvaot, o baño ceremonial. ${ }^{42}$

En el NT, los hogares de las personas son referidos indistintamente con los términos oıxı y oıxos, independientemente de la arquitectura del edificio. ${ }^{43}$ No obstante, ambos términos son diferentes, pues originalmente se refería a la vivienda propiamente dicha, mientras que oıxos incluía las propiedades domésticas y la familia. ${ }^{44}$ De hecho, ambos términos se usan no solo con su significado literal de vivienda, sino también en sentido metafórico para referirse a "familias" y "comunidades domésticas". ${ }^{45} \mathrm{Al}$ referirse a los hogares utilizados para reuniones eclesiásticas, usualmente se utiliza el término oıxos (Hch 2:2, 46; Ro 16:4; 1 Co 16:19; Col 4:15; Fil 1:2). ${ }^{46}$

La arquitectura de los lugares de reunión cristiana evolucionó con el tiempo en cuatro etapas más o menos definidas (véase la Tabla 2). ${ }^{47}$ En general, se asume que desde la década del 30 hasta el 150 aproximadamente, los cristianos se reunían en las casas de creyentes que ofrecían su morada para ese fin. Pero, en la segunda mitad del siglo II, los cristianos comenzaron a modificar deliberadamente sus hogares para alojar una mayor cantidad de personas. Generalmente una habitación era agrandada y dedicada específicamente para celebrar los cultos de adoración. Esta sección de la casa era denominada domus ecclesiae. Luego, a mediados del siglo III, en algunas regiones se comenzaron a construir salones rectangulares para alojar a la iglesia en sus cultos. Este lugar era llamado aula ecclesiae. Por último, a partir del 313 los cristianos comenzaron a construir basílicas, generalmente gracias al patronazgo del Imperio.

42 Magen Broshi, "The Archaeology of Palestine 63 BCE - CE 70", en The Early Roman, vol 3 de The Cambridge History of Judaism, ed. William Horbury, W. D. Davies y John Sturdy (Cambridge: Cambridge University Press, 1999), 3:10-11.

43 R. Weigandt, "oıxia”, Diccionario Exegético del Nuevo Testamento, ed. Horst Balz y Gerhard Schneider (Salamanca: Sígueme, 2002), 2:484-485; R. Weigandt, "oıxos", Diccionario Exegético del Nuevo Testamento, ed. Horst Balz y Gerhard Schneider (Salamanca: Sígueme, 2002), 2:501.

44 J. Goetzmann, “oıxos", NIDNTT, 2:247.

45 J. Goetzmann, "Casa”, Diccionario Teológico del Nuevo Testamento, ed. Erich Beyreuther, Hans Bietenhard y Lothar Coenen (Salamanca: Sígueme, 1990), 1:234.

46 Debe notarse que se usa oเxı $\alpha$ en Hechos 12:12.

47 Linton, "House Church Meetings", 230. 
La mayoría de las casas antiguas no podían alojar a más de 30 o 40 personas..$^{48}$ Estas congregaciones probablemente tenían como líder a la cabeza del hogar en el que se reunían. Al menos así lo parecen indicar las menciones neotestamentarias de iglesias cristianas. ${ }^{49}$ Las reuniones cristianas en los hogares incluían la lectura de las Escrituras, el canto ${ }^{50}$ y solía finalizar con una comida compartida entre los creyentes. ${ }^{51}$

Tabla 2 - Cronología y características de la arquitectura cristiana.

\begin{tabular}{|l|l|l|l|}
\hline \multicolumn{1}{|c|}{ Casa-iglesia } & Domus ecclesiae & \multicolumn{1}{c|}{ Aula ecclesiae } & \multicolumn{1}{c|}{ Basílica } \\
\hline $31-150$ & \multicolumn{1}{|c|}{ 150-250-313 } & 313 - en adelante \\
\hline $\begin{array}{l}\text { Hogares de } \\
\text { creyentes en } \\
\text { donde se } \\
\text { reunía la con- } \\
\text { gregación de } \\
\text { creyentes. }\end{array}$ & $\begin{array}{l}\text { Habitación del } \\
\text { hogar de un cre- } \\
\text { yente preparada } \\
\text { yedicada para } \\
\text { alojar a la iglesia. }\end{array}$ & $\begin{array}{l}\text { Salón rectangu- } \\
\text { lar utilizado } \\
\text { únicamente } \\
\text { para las reunio- } \\
\text { nes cristianos. }\end{array}$ & $\begin{array}{l}\text { Grandes edificios } \\
\text { dedicados especí- } \\
\text { ficamente para } \\
\text { reuniones cristia- } \\
\text { nas. }\end{array}$ \\
\hline
\end{tabular}

\subsection{Declive}

Mientras que durante el siglo I y la primera mitad del siglo II el cristianismo se mantuvo como una religión carismática y doméstica, para el siglo III era común que los creyentes se congregaran en domus eeclesiae. ${ }^{52}$ Tenemos evidencia histórica y arqueológica de varios de estos edificios, por ejemplo, la iglesia de Dura-Europos (s. III). ${ }^{53}$

48 Rafael Aguirre, Del movimiento de Jesús a la iglesia cristiana: Ensayo de exégesis sociológica del cristianismo primitivo (Estella: Verbo Divino, 2009), 105.

49 Valeriy A. Alikiin, The Earliest History of the Christian Gathering: Origin, Development and Content of the Christian Gathering in the First to Third Centuries (Leiden: Brill, 2010), 69.

50 John Arthur Smith, Music in Ancient Judaism and Early Christianity (Farham: Ashgate, 2011), 167-187.

51 Rafael Aguirre Monasterio, "Ritos de pertenencia: Comidas eucarísticas”, en Así vivían los primeros cristianos: Evolución de las prácticas y de las creencias en el cristianismo de los orígenes, ed. Rafael Aguirre Monasterio (Estella: Verbo Divino, 2017), 173-180.

52 Díaz Corrales y Flores Aparicio, “La iglesia de casa”, 91.

53 Robert Milbrun, Early Christian Art and Architecture (Berkeley, CA: University of California Press, 1988), 9-13. 
No obstante, es importante notar que la construcción de templos cristianos comenzó ya en el siglo III, aunque no parece haber sido una práctica extendida. Por ejemplo, la Crónica de Edesa (s. VI) asegura que el rey de dicha ciudad contaba con un templo cristiano ya en el año $201 .{ }^{54}$ El filósofo pagano Porfirio (232-304) aseguró que los cristianos "imitando nuestras costumbres, erigen templos y construyen grandes casas en las cuales se reúnen para orar, incluso aunque pueden hacer esto en sus propias casas". 55 Eusebio de Cesarea asegura que antes de la persecución de Dioclesiano, iniciada en el 303, "muchedumbres" de "miles de hombres" se congregaban en las reuniones cristianas, lo cual motivó que se levantaran "desde los cimientos, grandes iglesias de gran amplitud por todas las ciudades". ${ }^{56}$

De acuerdo a Eusebio de Cesarea, el edicto de Milán les dio a los cristianos la autorización de "edificar sus propias iglesias". ${ }^{57}$ En el año 324, bajo el auspicio del Emperador Constantino, comenzó la edificación sistemática de basílicas en donde los cristianos pudieran reunirse y adorar ${ }^{58}$ Además del patronazgo imperial, otros factores influyeron en el reemplazo de las casas-iglesias por basílicas. Por ejemplo, el canon 58 del concilio de Laodicea (c. 365) prohibió que la Eucaristía se realice en hogares particulares. ${ }^{59}$ Así, el uso regular de las casas de los creyentes como centro de reunión y adoración para la iglesia desapareció casi por completo a comienzos de la Edad Media, para resurgir recién durante la Reforma. ${ }^{60}$

\subsection{Beneficios de las casas-iglesias}

La utilización de las casas iglesias ciertamente proporcionó varios beneficios prácticos para la evangelización cristiana primitiva. Podemos resumir estas ventajas en cinco puntos generales.

54 Richardson, Building Jewish in the Roman East, 145.

55 R. Joseph Hoffman, Porphyry's Against the Christians: The Literary Remains (New York: Prometheus, 1994), 85.

56 Eusebio de Cesarea, Historia eclesiástica 8.1.5.

$57 \quad$ Ibid., 9.10.10.

58 Richardson, Building Jewish in the Roman East, 144.

59 Norbert Widok, "Christian Family as Domestic Church in the Writings of St. John Chrysostom", Studio Ceranea 3 (2013): 168.

60 Sergio Becerra, “La Edad Media y la Reforma: El caso de los valdenses y los anabaptistas", en Grupos pequeños: Profundizando la caminata, ed. por Jolivê Chaves y Alberto R. Timm (Buenos Aires: Asociación Casa Editora Sudamericana, 2011), 47-56.

https://doi.org/10.17162/recm.v18i1-2.1536 


\subsubsection{Adaptación y resiliencia}

Dado que prácticamente cualquier casa podía convertirse en un centro de reunión, el cristianismo podía esparcirse con facilidad en el mundo grecoromano. La plantación de iglesias se centraba en la evangelización y la formación de una comunidad de creyentes, sin necesidad de preocuparse en demasía del lugar para las reuniones cristianas. ${ }^{61}$ Además, en el caso de persecuciones populares o gubernamentales, los cristianos podían fácilmente reubicar sus reuniones o establecer nuevos centros de congregación.

\subsubsection{Fortalecimiento teológico de la comunidad de fe}

Mientras que en la actualidad el término iglesia describe usualmente el edificio físico donde se reúne una congregación, en el cristianismo primitivo esta palabra se refería únicamente a la comunidad de creyentes. ${ }^{62} \mathrm{El}$ foco eclesiológico de la comunidad estaba en sí misma, no en un espacio físico. Por lo tanto, se mantenía una comunión fraternal en todo lugar que los creyentes estuvieran juntos, convirtiendo la experiencia cristiana en una realidad cotidiana y constante en sus vidas (cf. Mt 18:20). El uso de ambientes domésticos como lugares de reuniones también facilitó la autopercepción de la congregación como una familia de "hermanos" y "hermanas" en Cristo. ${ }^{63}$ La comunidad de creyentes era la "casa de Dios" (1 Ti 3:15; Heb 3:6; 1 P 4:17).

La concepción de la iglesia como una fraternidad de hermanos provocó un sentido de horizontalidad en la comunidad de creyentes. Independientemente de la clase social, posición económica, raza, sexo o edad, todos eran miembros de la iglesia, iguales en Cristo Jesús. ${ }^{64}$

61 No debemos olvidar los costos aparejados a la construcción de templos y santuarios. La utilización de casas no solo era conveniente, sino también un método incomparablemente barato para los adoradores cristianos.

62 Comité de Investigación Bíblica de la División Intereuropea, La Iglesia de Cristo, su misión y su ministerio en el mundo (Barcelona: Aula7activa, 2009), 2-3.

63 Paul Trebilco, "Early Christian Communities in the Greco-Roman City: Perspectives on Urban Ministry from the New Testament", ExAud 29 (2013): 38.

64 Toribio Tapia Bahena, "La iglesia de casa desde la Sagrada Escritura”, en Para comprender la iglesia de casa, de la conservación a la misión, ed. Benjamín Bravo Pérez (Estella: Verbo Divino, 2010), 32.

https://doi.org/10.17162/recm.v18i1-2.1536 


\subsubsection{Inclusividad}

En el mundo greco-romano, y en la cultura palestina también, el hogar era visto como un ambiente típicamente femenino. ${ }^{65}$ Dado que la participación de mujeres en ambientes públicos estaba limitada por las convenciones y normas sociales de la época, la utilización de casas como lugares de reunión permitió la fácil evangelización de mujeres al cristianismo. De hecho, la evidencia señala que la evangelización femenina estuvo concentrada en ambientes domésticos. ${ }^{66}$

El uso de hogares como centros de reunión también permitió la participación activa de mujeres en puestos de liderazgo que normalmente le estaban socialmente vedados. Dado que el anfitrión era normalmente considerado como el líder de la reunión, las mujeres que "acogieran una reunión cristiana en su hogar serían altamente honradas, como benefactoras y como líderes". ${ }^{67}$

El NT proporciona algunos ejemplos de estas situaciones. María, la madre de Juan Marcos, Lidia de Filipos, Ninfas de Laodicea, entre otras, acogían iglesias en sus hogares y eran, presumiblemente, las líderes de estas congregaciones locales. ${ }^{68}$ Dado que la estructura administrativa de la iglesia estaba basada en la de la casa, el liderazgo femenino era considerado "no solo aceptable, sino también natural" ${ }^{69}$ En este sentido, la inclusividad social de las iglesias cristianas no tenía paralelo en el mundo antiguo. ${ }^{70}$

65 Fernando Rivas, La vida cotidiana de los primeros cristianos (Estella: Verbo Divino, 2011), 32; Kevin Giles, "House-Churches", Priscilla Papers 24, no. 1 (2010): 6-8.

66 Margaret Y. MacDonald, "Was Celsus Right? The Role of Women in the Expansion of Early Christianity", en Early Christian Families in Context: An Interdisciplinary Dialogue, ed. David L. Balch y Carolyn Osiek (Grand Rapids: Eerdmans, 2003), 183-184.

67 Jeanne Halgren Kilde, Sacred Power, Sacred Space: An Introduction to Christian Architecture and Worship (New York: Oxford University Press, 2008), 31.

68 Margaret Y. MacDonald, Carolyn Osiek y Janet H. Tulloch, El lugar de la mujer en la iglesia primitiva (Salamanca: Sígueme, 2007), 223-226; Jory Peterson, "A Study of Female Headship in the Christian Church During the First and Second Century and How this Applies to Female Leadership in the Church Today" (Tesis de maestría, Regent University, 2010), 15-17.

69 Karen Jo Torjesen, Cuando las mujeres eran sacerdotes (Córdoba: El Almendro, 1996), 90.

70 Alan Kreider, Worship and Evangelism in Pre-Christendom (Cambridge: Grove Books, 1995), 18. 
3.4.4. Mayores oportunidades sociales para

la predicación

Todas las casas-iglesias identificadas en el NT estaban ubicadas en grandes centros urbanos o en ciudades clave en las rutas comerciales. Probablemente esto se deba a que en las ciudades había una mayor cantidad de personas para evangelizar y también "una mayor apertura y disposición a escuchar a predicadores de nuevas religiones". ${ }^{71}$

Además de esto, la hospitalidad característica de los judíos y las reglas domésticas greco-romanas permitían que los visitantes pudieran dialogar, evangelizar y convertir a los miembros de las familias anfitrionas. De hecho, es notable que varios casos de conversiones en el NT se producen en contextos domésticos (Hch 9:11, 17; 10:24-48; 16:31-33).

La evidencia sugiere que la casa era "la principal plataforma para la evangelización" de los cristianos apostólicos.72 Hasta el punto que incluso las decoraciones de las casas eran utilizadas por los cristianos para atraer el interés y la atención de sus visitantes paganos con la intención de evangelizarlos. ${ }^{73}$ Debe notarse también lo siguiente, siendo que la base del evangelismo era el hogar, y de este, la mujer, en consecuencia su función doméstica fue decisiva en la evangelización cristiana apostólica. ${ }^{74}$

\subsubsection{Evangelización a familias}

Al predicar dentro de las casas se tenía la posibilidad de alcanzar a toda la familia. Especialmente si la cabeza del hogar se convertía pues, según la costumbre, toda la familia debía practicar la misma religión.

Aparentemente, los apóstoles buscaban intencionalmente predicar en los hogares pues el NT registra que predicaban "todos los días, en el templo y de casa en casa" (Hch 5:42, cf. 20:20; 28:17). La predicación en los hogares llevó a la conversión de numerosas familias, ${ }^{75}$ como la de Cornelio (Hch 10:24, 44-48), Lidia (Hch 16:14-15), el carcelero de Filipos (Hch 16:32-34), Crispo el corintio (Hch 18:8) y Estéfanas (1 Co 1:16). Presumiblemente, estas

71 Abraham J. Malherbe, Social Aspects of Early Christianity (Baton Rouge, LO: Lousiana State Universtiy Press, 1977), 63.

72 Santiago Guijarro Oporto, La primera evangelización (Salamanca: Sígueme, 2013), 83.

73 Michael Green, La evangelización en la iglesia primitiva (Buenos Aires: Nueva Creación, 1997), 377-380.

74 Gillian Cloke, "Women, Worship and Mission: The Church in the Household", en The Early Christian World, ed. Philip F. Esler (London: Routledge, 2002), 447.

75 Aguirre, Del movimiento de Jesús, 84. 
familias adoraban en sus propios hogares, que se convertirían eventualmente en nuevas casas-iglesias.

La estrategia de predicar en las casas proviene de Jesús mismo, quien instruyó a los apóstoles a visitar los hogares de las personas durante sus viajes misioneros (Mt 10:12-14, cf. Lc 10:1-7). Además, la evidencia sugiere que el hogar era considerado como el primer campo evangelístico de los primeros conversos. ${ }^{76}$ Por ejemplo, en numerosos escritos patrísticos se menciona a mujeres que convertían a sus esposos paganos. ${ }^{77}$ Por último, debemos mencionar que las casas-iglesias también se convirtieron en centros informales de instrucción para los nuevos $\operatorname{conversos}^{78} \mathrm{y}$ en bases de apoyo material para misioneros y apóstoles. ${ }^{79}$

\section{Las casas-iglesias en la actualidad}

A pesar de la completa ausencia de templos en el cristianismo primitivo, visualizar la iglesia hoy sin ellos parece imposible. La gran mayoría de las denominaciones han elegido mantener el uso de templo, incorporando, a lo sumo, la implementación de grupos pequeños o células. No obstante, la utilización de casas-iglesias aún tiene sólidos defensores dentro de cristianismo, incluyendo la IASD ${ }^{80}$ Usualmente se apela a la evidencia bíblica en favor de las casas-iglesias, aunque también existe evidencia empírica para sustentar esta práctica.

76 Por ejemplo, luego de liberar al endemoniado gadareno, Jesús le ordenó “Vete a tu casa, a los tuyos, y cuéntales cuán grandes cosas el Señor ha hecho por ti" (Mr 5:19; cf. Mr 6:10 y Lc 8:39).

77 Gustavo Bardy, La conversión al cristianismo durante los primeros siglos (Madrid: Encuentro, 1990), 199-200.

78 David Dunn-Wilson, A Mirror for the Church: Preaching in the First Five Centuries (Grand Rapids: Eerdmans, 2005), 14.

79 David G. Hunter, "The Domestic Church and the Early Church: The Household as Context for Christianization in Late Antiquity", en The Household of God and Local Households: Revisiting the Domestic Church, ed. Thomas Knieps-Port Le Roi, Gerard Mannion y Peter de Mey (Leuven: Peeters, 2013), 221.

80 Russell Burrill, La iglesia revolucionada del siglo XXI (Buenos Aires: Asociación Casa Editora Sudamericana, 2007).

https://doi.org/10.17162/recm.v18i1-2.1536 
Dentro de la IASD se han registrado numerosos casos en los que la implementación de casas-iglesias ha conseguido retener a los miembros, evangelizar a las personas y avanzar en el crecimiento de la iglesia. En lugares tan dispares como Estados Unidos, ${ }^{81}$ China, ${ }^{82}$ Australia ${ }^{83}$ y Corea del Sur. ${ }^{84}$

\subsection{Ventajas evangelísticas}

A partir del estudio histórico realizado, podemos notar que muchos de los beneficios y ventajas que proporciona el uso de casas-iglesias persisten en la actualidad. No obstante, dos grandes diferencias existen debido a los cambios socio-culturales producidos en este tiempo.

Para empezar, aunque las ciudades continúan teniendo una mentalidad más liberal y abierta a nuevas ideas y religiones, el cristianismo ha dejado de ser una novedad y se ha convertido en una religión tradicional. La población actual está más abierta a religiones innovadoras que a una fe antigua. Segundo, los avances sociales respecto a la discriminación racial, el combate de la pobreza y la desigualdad de género han provocado que vivamos en una civilización notablemente más inclusiva e igualitaria, al menos en comparación con tiempos pasados.

Estos cambios sociales han hecho irrelevantes algunas de las ventajas que las casas-iglesias proporcionaban a los cristianos primitivos. Sin embargo, algunas características de la sociedad actual pueden ser explotadas con éxito por la iglesia mediante las casas-iglesias.

\subsubsection{Sentido de pertenencia y contención}

La población urbana actual está perdiendo el sentido de comunidad, pero al mismo tiempo "están hambrientos de comunión íntima y duradera". 85 Una iglesia reunida en una casa puede proporcionar la contención emocional y espiritual que mucha gente necesita. Aunque muchas personas se resistirían a ingresar a una iglesia, la casa provee un contexto doméstico y

81 W. Milton Adams, "Developing, Planting and Multiplying an Adventist House Church Using Principles of Missiology in the Florida Conference of Seventh-day Adventists" (Tesis de doctorado, Andrews University, 2009).

82 Jie Kang, House Church Christianity in China: From Rural Preachers to City Pastors (Londres: Palgrave Macmillan, 2016), 72-80.

83 Peter Fowler, "House Churches: Western Australia", Record, julio de 2011, 20.

84 Won Moo Song, "A Paradigm for Cell Church Ministry in the Seventh-day Adventist Church in South Korea" (Tesis de doctorado, Andrews University, 2010).

85 David Barnes, "El mundo urbano y globalizado: implicaciones para la iglesia", Kairós 49 (2011): 96. 
neutro. El éxito de los grupos pequeños de personas para proporcionar contención emocional y espiritual ha sido ampliamente estudiado y aceptado. ${ }^{86}$

\subsubsection{Instalaciones baratas y versátiles}

Al utilizar casas para alojar reuniones cristianas se evitan los gastos de adquirir, construir y/ o mantener un edificio para ese fin..$^{87}$ Debe notarse que muchas iglesias pequeñas gastan la mayoría de sus ingresos en el mantenimiento de sus templos. ${ }^{88}$

Aunque la posibilidad de persecuciones populares o gubernamentales es prácticamente inexistente en la mayor parte del mundo occidental, el uso de casas-iglesias continúa siendo prevalente en regiones del mundo en que el cristianismo sufre de censura o represión. ${ }^{89}$ La versatilidad que las casasiglesias proporcionaban al cristianismo primitivo continúa siendo útil en algunas regiones del mundo.

4.1.3. Fortalecimiento de la eclesiología biblica

La utilización de templos ha favorecido la separación entre el clero y el laicado, ha minimizado la importancia de la comunidad de fe y dificulta la introducción de nuevos conversos a la congregación..$^{90}$ Las iglesias numerosas tampoco proporcionan un ambiente acogedor que si puede ser alcanzado mediante grupos más pequeños reunidos en hogares.

El uso de casas-iglesias, en cambio, permite la implementación del sacerdocio de todos los creyentes, recuperando la horizontalidad apostólica, llevando "la iglesia a las personas", y afirmando la importancia de la comunidad como familia en Cristo. ${ }^{91}$

\subsubsection{Ventajas sociales para la predicación}

Muchas personas en centros urbanos sienten reticencia a ingresar a templos debido a prejuicios religiosos. La implementación de cultos en ambientes domésticos permite evadir estas aprensiones y lograr una incorporación

86 Robert Wuthnow, Sharing the Journey: Support Groups and America's New Quest for Community (New York: Simon \& Schuster, 1994), 176.

87 Wolfgang Simson, Casas que transformarán el mundo: El retorno de las iglesias a los hogares (Barcelona: CLIE, 2003), 62.

88 Ibíd.

89 Ibíd., 59.

$90 \quad$ Ibíd., 35-36.

91 Ibíd., 19-21. 
más sencilla de nuevos conversos a la comunidad de creyentes. Por ejemplo, el pastor adventista Carlos Manzanillo afirma: "la asistencia a las casas es mayor que la asistencia de los sábados al templo. Esto no porque asistan más hermanos, sino por la abrumadora cantidad de amigos que prefiere ir a una casa, que al templo". ${ }^{92}$ En este sentido, las estadísticas comprueban que el número de "visitas" a cultos de adoración en casas es considerablemente superior al de los cultos en iglesias. ${ }^{93}$

\section{Conclusión}

En esta investigación hemos podido observar que la utilización de casasiglesias le permitió al cristianismo primitivo trabajar con efectividad en los centros urbanos antiguos. A pesar de las diferencias culturales, sociales e históricas entre ese período y la actualidad, algunos de los beneficios persisten. El uso de las casas como centro primario de reunión de los creyentes permite generar un ambiente familiar que ayuda a la incorporación de nuevos conversos a la iglesia, es una alternativa mas económica y versátil en comparación a los templos además de que fortalece conceptos eclesiológicos clave de la Escritura.

El uso de las casas-iglesias ya ha probado ser un éxito en otras regiones del mundo y bien podría serlo en el contexto actual para alcanzar a las multitudes que viven en los grandes centros urbanos.

92 Carlos Manzanillo, Haciendo discípulos en grupos pequeños: Cómo multiplicar grandemente el número de creyentes (Santo Domingo: Edición del autor, 2011), 114.

93 Isabel Rode y Daniel Rode, Crecimiento: Claves para revolucionar su iglesia (Buenos Aires: Asociación Casa Editora Sudamericana, 2003), 91-92.

https://doi.org/10.17162/recm.v18i1-2.1536 